\section{MS36-O5 Structural similarity in homologous families: the case of mandelic acids}

Graham J. Tizzard ${ }^{1}$, Simon J. Coles ${ }^{1}$, Amy L. Ellis ${ }^{1}$, Ka Leung ${ }^{1}$, Jonathan Sarson ${ }^{1}$, Terence L. Threlfall ${ }^{1}$

1. Chemistry, Faculty of Natural and Environmental Sciences, University of Southampton, UK

email: gjt1@soton.ac.uk

For several years we have been making detailed comparisons of the crystal structures of large sets of related compounds in an attempt to understand the factors determining the adoption of particular molecular arrangements within crystal structures [1-3].

As part of a larger crystallographic project to investigate the relationship between structure and chirality, we have synthesised and determined crystal structures of families of monosubstituted racemic mandelic acids (MAs) with fluoro, chloro, bromo, iodo, trifluoromethyl, methyl and methoxy substituents at the ortho, meta and para positions. Of these 21 permutations only four were previously described in the literature [4-7].

These have been investigated for structural similarity using the XPac software [8]. The results, presented pictorially as a structural relationship plot, show that rather more structures are built up from the carboxyl-chain hydroxyl hydrogen bonded dimer than from the conventional carboxylic acid dimer. The results show how all the structures are related and, based on the two types of dimer, the degree of similarity that they possess. Some structures with $Z^{\prime}>1$ contain both sorts of dimers and there are many examples of isostructural sets. By analysing similarity in this related family of structures, both trends and gaps can be identified - for example a structure that should be present has been identified and subsequently synthesised and determined [9].

For the next stage of this study we are now investigating the co-crystallisation behaviour of the substituted racemic mandelic acids with enantiomerically pure phenylethylamine.

[1] Hursthouse, M. B., Montis, R., Tizzard, G. J., (2010), CrystEngComm, 12, 953-959

[2] Hursthouse, M. B., Montis, R., Tizzard, G. J., (2011), CrystEngComm, 13, 3390-3401

[3] Gelbrich, T., Threlfall, T. L., Hursthouse, M. B., (2012), Acta Cryst. C10, O421-U299

[4] Larsen, S. and Marthi, K., (1994), Acta Cryst. B, 50, 373-381

[5] Larsen, S. and Marthi, K. (1997), Acta Cryst. B, 53, 280-292

[6] He, Q., Zhu, J., Gomaa, H., Jennings, M., Rohani, S., (2009), J. Pharm. Sci., 98 1835-1844

[7] He, Q., Rohani, S., Zhu, J., Gomaa, H., (2010), Cryst.Growth Des., 10 5136-5145

[8] Gelbrich, T., Hursthouse M. B. (2005), CrystEngComm, 7, 324-336

[9] Coles, S. J., Ellis, A. L., Leung, K., Sarson, J., Threlfall, T. L., Tizzard, G. J., (2014), CrystEngComm, $16,10816-10823$.

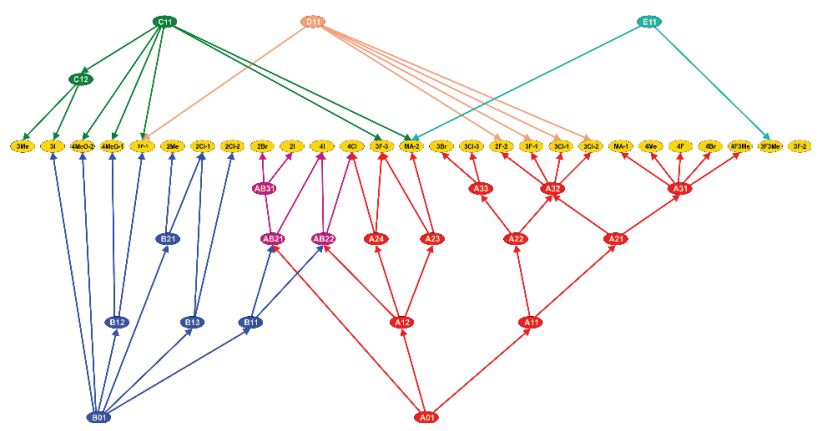

Figure 1. Structural relationship diagram for substituted racemic MAs. Yellow nodes are crystal structures. Blue and red nodes show packing similarities based on 8- and 10- membered $\mathrm{H}$-bonded dimer rings respectively and purple nodes are based on both. Other colour nodes show non-dimeric similarities

Keywords: Mandelic acid, strutural similarity 